\title{
Novel Vorinostat Analogues with Improved HDAC Inhibition, Stronger Cytotoxic Effect and Higher Selectivity Against Leukemias and Lymphomas
}

\author{
Bartosz Bieszczad, ${ }^{1,+}$ Damian Garbicz, ${ }^{1,+}$ Marta Świtalska, ${ }^{2}$ Marta K. Dudek, ${ }^{3}$ Dawid Warszycki, ${ }^{4}$ Joanna Wietrzyk, ${ }^{2}$ \\ Elżbieta Grzesiuk,1* Adam Mieczkowski ${ }^{1 *}$ \\ 1 Institute of Biochemistry and Biophysics, Polish Academy of Sciences, Pawińskiego 5a, 02-106 Warsaw, \\ Poland; b.bieszczad@ibb.waw.pl (B.B.), dgarbicz@ibb.waw.pl (D.G.); elag@ibb.waw.pl (E.G.); \\ amiecz@ibb.waw.pl (A.M.) \\ 2 Hirszfeld Institute of Immunology and Experimental Therapy, Polish Academy of Sciences, R. Weigla 12 \\ Street, 53-114 Wrocław, Poland; marta.switalska@hirszfeld.pl (M.Ś), joanna.wietrzyk@hirszfeld.pl (J.W.); \\ 3 Centre of Molecular and Macromolecular Studies, Polish Academy of Sciences, Sienkiewicza 112, 90-363 \\ Lodz, Poland; mdudek@cbmm.lodz.pl (M.K.D); \\ 4 Maj Institute of Pharmacology, Polish Academy of Sciences, Smętna 12, 31-343 Cracow, Poland; \\ warszyc@if-pan.krakow.pl (D.W.) \\ * Correspondence: amiecz@ibb.waw.pl; elag@ibb.waw.pl; Tel.: +48-22-592-3506 \\ + These authors contributed equally to this work.
}

\begin{abstract}
Simple Summary: Histone deacetylase (HDAC) inhibitors are an emerging class of drugs used in the cancer treatment. Despite their undoubted therapeutic utility, HDAC inhibitors show a number of side effects, which entails searching and developing new, more effective and selective agents inhibiting HDAC activity but also showing a narrower range of undesirable symptoms. In our research, we designed, developed and synthesized a library of 19 new analogues of Vorinostat, an HDAC inhibitor used in lymphomas treatment but also considered as possible anticancer compound for other types of cancer. The main structural modification consisted in replacing the phenyl group with a tricyclic system with a central eight-membered heterocyclic ring, which led to the novel Vorinostat analogues with improved HDAC inhibition, stronger cytotoxic effect and higher selectivity against leukemias and lymphomas.
\end{abstract}

\begin{abstract}
Histone deacetylase (HDAC) inhibitors are class of drugs used in the cancer treatment. Here, we developed a library of 19 analogues of Vorinostat, an HDAC inhibitor used in lymphomas treatment. In Vorinostat, we replaced the hydrophobic phenyl group with various tricyclic 'caps' possessing a central, eight-membered, heterocyclic ring, and investigated the HDAC activity and cytotoxic effect on the cancer and normal cell lines. We found that three out of the 19 compounds, based on dibenzo $[b, f]$ azocin- $6(5 H)$-one, 11,12-dihydrodibenzo $[b, f]$ azocin- $6(5 H)$-one and benzo[ $b]$ naphtho[2,3- $f][1,5]$ diazocine-6,14 $(5 H, 13 H)$-dione scaffolds, showed better HDACs inhibition than the referenced Vorinostat. In leukemic cell line MV4-11 and in lymphoma cell line Daudi three compounds showed lower IC 50 values than Vorinostat. These compounds had higher activity and selectivity against MV4-11 and Daudi cell lines than reference Vorinostat. We also observed a strong correlation between HDACs inhibition and the cytotoxic effect. Cell lines derived from solid tumors: A549 (lung carcinoma) and MCF-7 (breast adenocarcinoma) as well as reference Balb/3T3 (normal murine fibroblasts) were less susceptible to compounds tested. Developed derivatives show superior properties than Vorinostat, thus they are applicable as selective agents for leukemia and lymphoma treatment.
\end{abstract}

Keywords: Vorinostat, histone deacetylase, HDAC inhibitors, dibenzodiazocines, hydroxamic acid, selectivity

\section{Introduction}


Histone deacetylases (HDAC) are an important group of enzymes playing diverse biological roles in living cells [1-4]. Dysregulation of HDAC expression could be associated with various human malignancies [5-7], thus they focused the attention of medicinal chemists as potential molecular targets. To date, research efforts have been largely directed to the use of HDAC inhibitors as potential anti-cancer agents [8-13]. Nevertheless, other applications such as anti-inflammatory [14-19], antifibriotic [20-24] or neuroprotective effect in Huntington's disease [25-27], Alzheimer disease [27,28], spinal muscular atrophy [29] or Friedreich's ataxia were studied [30]. HDAC inhibitors were postulated as possible therapeutic agents in asthma and chronic obstructive pulmonary disease (COPD) [31], methamphetamine addiction [32], heart failure [33-35], diabetes [36,37], depression [38] or suppression of aging processes [39]. They were also tested for potential antimicrobial and anti-infective activities as antiviral [40-42], antibacterial [43], antifungal [44,45] or antiparasitic [46-48] agents. In anticancer therapy, the HDAC inhibitors were tested as therapeutic agents for different type of tumors including but not limited to glioblastoma [49], multiple myeloma [50-52], T-cell lymphoma [53], breast cancers [54] and lymphoproliferative disorders [55-57]. The anticancer effect of HDAC inhibitors could be further potentiated by application of combined therapy together with other antitumor agents with a different mode of action [58] such as epigallocatechin-3-gallate (EGCG), a DNA methyltransferase (DNMT) inhibitor [59], cisplatin, a metalating agent [60], gemcitabine interfering nucleic acid synthesis [61], decitabine, a hypomethylating agent inhibiting DNA methyltransferase [62], doxorubicin [63] and ellipticin [64] DNA intercalators and topoisomerase II inhibitors, Temozolomide, an alkylating agent [65], proteasome inhibitors [66], BET (bromodomain and extraterminal domain proteins) inhibitors [67] and RG7388, an inhibitor of tumor-associated protein MDM2 [68]. The antitumor effect of HDAC inhibitors was also combined with photodynamic therapy [69], radiation therapy (increasing radiation sensitivity) [70-72] and application of oncolytic viruses $[73,74]$.

Although several natural products were identified as HDAC inhibitors [75,76], most of them were obtained by chemical synthesis [77]. The first successful HDAC inhibitor bearing hydroxamic acid moiety - Vorinostat (SAHA, suberanilohydroxamic acid, Zolinza (B) (1) [78,79] was successfully used in the treatment of cutaneous T-cell lymphoma and its further analogues Belinostat (peripheral T-cell lymphoma), Panbinostat (multiple myeloma) and other types of HDAC inhibitors: Romidepsin (cutaneous T-cell lymphoma) and Chidamide (peripheral T-cell lymphoma), were approved by FDA for cancer treatment [80]. However, it should be taken under consideration that HDAC inhibitors can cause a number of side effects [81] and their potential use and success in cancer therapy is highly dependent on difficulties to achieve selectivity, decrease toxicity and reduce the adverse effects [82,83]. For this reason, new generations of HDAC inhibitors with an improved pharmacological profile and greater selectivity for cancer cells are intensively studied and developed [84].

The basic structural features of Vorinostat (1) and its analogues include the non-polar aromatic/heteroaromatic cap and a side chain with a terminal hydroxamic acid group capable of binding to zinc ions $\mathrm{Zn}^{2+}$. During research on new Vorinostat analogues, compounds 2-6 having a bicyclic or tricyclic benzodiazepine ring system (Figure 1) were also obtained [85-88] exhibiting marked HDAC inhibition and selective antileucemic effect on tested cell lines. 
<smiles>O=C(CCCCCCC(=O)Nc1ccccc1)NO</smiles><smiles>CC(C)C(=O)N1CCN=C(c2ccccc2)c2ccccc21</smiles>

4<smiles>[R]C1N=C(c2ccccc2)c2cc(C#CC(=O)NO)ccc2N1C</smiles><smiles>CC(C)C(=O)NC1N=C(c2ccccc2)c2ccccc2N(C)C1=O</smiles>

5<smiles>[R]C1N=C(c2ccccc2)c2cc(NC(=O)NO)ccc2N1C</smiles><smiles>[R]c1ccc([X])c(C(=O)N(C)c2ccccc2C(=O)NO)c1</smiles>

6

Figure 1. Vorinostat (1) and its analogues 2-6 based on benzodiazepine scaffolds.

For years our research group has been working on the design and synthesis of various mono- and polycyclic dilactam derivatives [89-98] with potential biological activity. The studies resulted in the discovery of tricyclic benzodiazepines exhibiting selective antileukemic effect [92-94]. These compounds could be treated as structural analogues of antitumor antibiotic Anthramycin. Recently, we focused on the development of novel synthetic methods leading to asymmetrically substituted tricylic lactam and dilacam compounds with central, eight-membered heterocyclic rings [95-97]. Such structures were used by us for the development of novel analogues of tricyclic drugs, which exhibited significant affinity to $\mathrm{H}_{1}$ receptors [98]. We envisioned then, that tricyclic heterocycles with two outer benzene rings and central, azocine or diazocine ring 7 (Figure 2) could be useful scaffolds in the design of novel analogues of Vorinostat, HDACs inhibitor used for lymphoma treatment [99]. We decided to replace the phenyl group in Vorinostat with various tricyclic 'caps' and investigate the HDACs activity as well as potency and selectivity of the cytotoxic effect tested on the cancer and non-cancer cell lines.

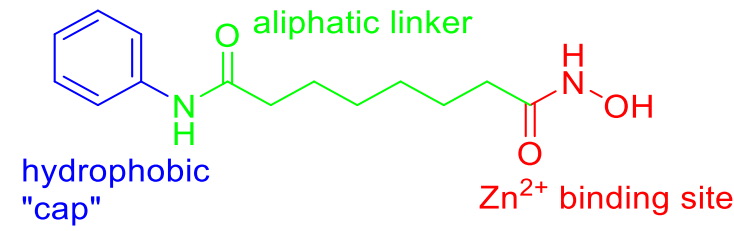

1

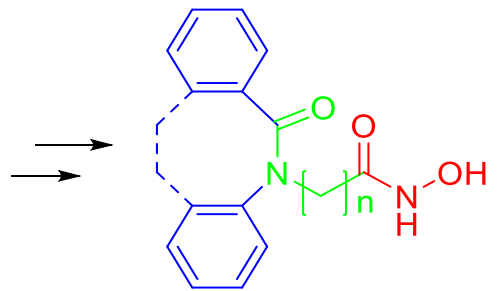

7

Figure 2. Concept of research, development of novel tricyclic analogues of HDAC inhibitor, Vorinostat.

\section{Materials and Methods}

\subsection{Chemistry}

Commercially available chemicals were of reagent grade and used as received. The reactions were monitored by thin layer chromatography (TLC), using silica gel plates (Kieselgel 60F254, E. Merck, Darmstadt, Germany). Column chromatography was performed on silica gel 60 M (0.040-0.063 mm, E. Merck, Darmstadt, Germany). Melting points are uncorrected and were measured on a Büchi (New Castle, DE, USA) Melting Point B-540 apparatus. All ${ }^{1} \mathrm{H}$ and ${ }^{13} \mathrm{C}$ NMR spectra were registered with a Bruker Avance III spectrometer operating at 500.13 and $125.77 \mathrm{MHz}$ for ${ }^{1} \mathrm{H}$ and ${ }^{13} \mathrm{C}$, respectively, and equipped with a $5 \mathrm{~mm}$ probe head with Z-gradient coils. The experiments were performed using pulse programs from standard Bruker library for samples dissolved in 
$\mathrm{CDCl}_{3}, \mathrm{DMSO}-d_{6}$ or $\mathrm{MeOH}-d_{4}$. In each case spectra were calibrated at residual solvent resonances. High resolution mass spectra were performed by the Laboratory of Mass Spectrometry, Institute of Biochemistry and Biophysics PAS, on a LTQ Orbitrap Velos instrument, Thermo Scientific (Waltham, MA, USA). Synthetic procedures, physicochemical properties and spectra related to synthesized compounds are included in the supplementary file.

\subsection{Biology}

\subsubsection{Cell Culturing}

MV4-11 (human, biphenotypic B myelomonocytic leukemia) and Daudi (human, Burkitt's lymphoma) cell lines were cultured in RPMI640 medium (Hirszfeld Institute of Immunology and Experimental Therapy, Polish Academy of Science (HIIET PAN), Wrocław, Poland) supplemented with 10\% fetal bovine serum (FBS), 2 mM L-glutamine and $1 \mathrm{mM}$ sodium pyruvate (all from Sigma).A549 (human, lung cancer) cell line was cultured in RPMI1640+OptiMEM (50:50; HIIET PAN, Wrocław, Poland) with 5\% FBS, 2 mM L-glutamine (all from Sigma). MCF-7 (human, adenocarcinoma, breast cancer) cell line was cultured in Eagle medium (HIIET PAN) with 10\% FBS (Sigma), 2 mM L-glutamine, $8 \mu \mathrm{g} / \mathrm{mL}$ insulin, 1\% amino acids (all from Sigma). Balb/3T3 (mouse, fibroblast) cell line was cultured in DMEM medium (Gibco) supplemented with 10\% FBS, 2 mM L-glutamine (all from Sigma). All cultured media were supplemented with $0.1 \%$ antibiotics: penicillin (Polfa Tarchomin, Warsaw, Poland) and streptomycin (Sigma). Cells were grown in a humidified atmosphere of CO2/air (5/95\%) at $37^{\circ} \mathrm{C}$.

\subsubsection{Histone Deacetylase Activity Assay (HDACs activity)}

In order to measure histone deacetylase activity, Histone Deacetylase Activity Assay (HDACAA) (Sigma) was used (Catalog Number CS1010). The HDACAA kit is based on a two-step enzymatic reaction. The substrate for the reaction is a substituted peptide with an acetylated lysine residue and a bound fluorescent group. The first step of the reaction is deacetylation of the acetylated lysine side chain by the HDAC containing sample (HeLa cell extract). The second step is the cleavage of the deacetylated substrate with the developer solution and the release of the free highly fluorescent group. The experiment was carried out according to the manufacturer's protocol. The following concentrations were used: $0.1,0.5,1$ and $2 \mu \mathrm{M}$. All calculations were done using Origin 9.0 software.

\subsubsection{Histone Deacetylase 8 Activity Assay}

In order to measure histone deacetylase 8 activity, Histone Deacetylase 8 Activity Assay (Sigma) was used. The HDAC8 acts with the supplied Developer, to deacetylate and then cleave the HDAC8 Substrate (R-H-K(Ac)-K(Ac)-AFC). The experiment was carried out according to the manufacturer's protocol. The following concentrations were used: $0.5,1,1.5,2,3$ and $4 \mu \mathrm{M}$. All calculations were done using Origin 9.0 software.

\subsubsection{Cytotoxicity Assay}

Exponentially growing cells were seeded onto a 96-well plate at the density of 104 cells/well (MV4-11, Daudi, Balb/3T3), 0.75x104 cells/well (MCF-7) or 0.5x104 cells/well (A549), cultured for $24 \mathrm{~h}$, and treated for $72 \mathrm{~h}$ with newly synthesized Vorinostat derivatives at concentrations of 50,10,2, 0.4 , and $0.008 \mu \mathrm{M}$, or with medium alone as a control. Proliferation inhibition readings were made using MTT (MV4-11and Daudi) or SRB (MCF-7, A549 and Balb/3T3) method.

SRB: $50 \mu \mathrm{L} 50 \%$ cold trichloroacetic acid (TCA) solution was added to wells and incubated for $1 \mathrm{~h}$. The plates were rinsed with distilled water, and after drying on a paper towel, $50 \mu \mathrm{L}$ of a $0.1 \%$ solution of sulforodamine B in $1 \%$ acetic acid was added and incubated for $30 \mathrm{~min}$ at room temperature. Subsequently, the plates were washed with $1 \%$ acetic acid and after desiccation of excess acid, $150 \mu \mathrm{L}$ of $10 \mathrm{mM}$ TRIS was added. After another $30 \mathrm{~min}$, the optical density of individual samples was read at $540 \mathrm{~nm}$ using a plate reader (Synergy H4 Hybrid Reader). 
MTT: $20 \mu \mathrm{L}$ MTT solution (5 mg/mL) was added to wells and plates were placed in an incubator. After $4 \mathrm{~h}$ of incubation at $37^{\circ} \mathrm{C}, 80 \mu \mathrm{L}$ of lysis buffer (SDS, DMF and water) was added and incubation continued for $24 \mathrm{~h}$. The optical density of individual samples was read at a wavelength of $570 \mathrm{~nm}$ using a plate reader (Synergy H4 Hybrid Reader).

All experiments were carried out at least three times with three replicates for each inhibitor concentration.

\subsection{In silico modelling}

\subsubsection{Compounds preparation}

The appropriate ionization states at $\mathrm{pH}=7.4$ for all structures used in docking procedures were assigned using Epik software. 3D structures were generated in Ligprep software under default settings (force field used OPLS2005, retention of specified chiralities and generation of only one low energy ring conformation per ligand).

\subsubsection{Docking protocol}

All receptors were centered at zinc ion located in a binding pocket with the grid box size set to $25 \times 25 \times 25 \AA$. Docking runs were performed in Glide software at the SP level under default settings (sampling nitrogen inversion, sampling ring conformations with energy window equal to $2.5 \mathrm{kcal} \cdot \mathrm{mol}-1$, penalizing nonplanar conformation of amides, up to 100 steps during energy minimization and performing post-docking optimization). Docking was carried up with one constraint - mandatory coordination of zinc ion.

\section{Results and discussion}

\subsection{Synthesis and HDAC inhibition}

Since increasing the size of the hydrophobic 'cap' in the Vorinostat structure could have had an impact on the optimal length of the side chain terminated with hydroxamic acid, in the first part of our research, we decided to synthesize two homologous series of compounds and used two selected tricyclic 'caps': 5-methyldibenzo[ $b, f][1,5]$ diazocine-6,12(5H,11H)-dione (8) [95] (Series 1) and dibenzo[b,f]azocin-6(5H)-one (9) [98] (Series 2) and different side chain lengths (Scheme 1).<smiles>CN1C(=O)c2ccccc2NC(=O)c2ccccc21</smiles>

8<smiles>O=C1Nc2ccccc2C=Cc2ccccc21</smiles>

9

a)<smiles>[R]OC(=O)N1C(=O)c2ccccc2N(C)C(=O)c2ccccc21</smiles>

$$
\text { 10a } \mathrm{n}=1
$$

$$
10 \mathrm{~b} n=2
$$

$10 \mathrm{c} n=3$

$10 d n=4$

10 e $n=5$

$10 f n=6$<smiles>[R]OC(=O)N1C(=O)c2ccccc2/C=C\c2ccccc21</smiles>

$\log n=1$

$10 \mathrm{~h} \mathrm{n}=2$

$10 \mathrm{i} n=3$

$10 \mathrm{j} n=4$

$10 k n=5$

101 $n=6$<smiles>CN1C(=O)c2ccccc2N(CC(=O)NO)C(=O)c2ccccc21</smiles>

$7 a_{n}=1$

$7 b \mathrm{n}=2$

$7 \mathrm{c} n=3$

$7 d \mathrm{n}=4$

$7 e n=5$

7f $n=6$

b)<smiles>Cn1c(=O)c2ccccc2ccc2ccccc2n1C(=O)NO</smiles>

$7 g n=1$

$7 \mathrm{~h} n=2$

$7 \mathrm{i} n=3$

$7 \mathrm{j} n=4$

$7 \mathrm{k} n=5$

7II $\mathrm{n}=6$

Scheme 1. The synthesis of the first 7a-f and second $7 g-1$ series of compounds: a) $\mathrm{Br}\left(\mathrm{CH}_{2}\right) \mathrm{nCOOR}$, $\mathrm{NaH}, \mathrm{DMSO}, 18 \mathrm{~h}, \mathrm{rt}, \mathrm{n}=1-6, \mathrm{R}=\mathrm{Me}, \mathrm{Et} ; \mathrm{b}) \mathrm{NH}_{2} \mathrm{OH} \times \mathrm{H}_{2} \mathrm{O}, \mathrm{THF}, \mathrm{MeOH}, 18 \mathrm{~h}$, rt. 
Previously obtained compounds $\mathbf{8}$ and $\mathbf{9}$ were treated with appropriate $\omega$-bromoester, in the presence of sodium hydride resulting in intermediate products 10a-1. After chromatographic purification and isolation, esters 10a-1 were treated with hydroxylamine hydrate which led to the final hydroxamic acids $7 \mathbf{a}-1$.

A standard fluorimetric HDACs inhibition kit (Sigma-Aldrich) was to determine the inhibitory potency of novel Vorinostat analogues. It involves a two-step enzymatic reaction: deacetylation of the peptide acetylated lysine side chain by the HDACs containing HeLa cell extract followed by a cleavage of the deacetylated substrate by the developer solution and the release of the highly fluorescent group. We evaluated the efficacy of HDACs inhibition activity of 12 newly synthesized Vorinostat derivatives and observed a correlation between the side chain length and the HDACs inhibition activity (Figure 3). The obtained results for Series 1 and 2 are presented in Table 1 . In both series the compounds with five-carbon atom linkers $(n=5)$ were the most active ones, additionally compound 7k demonstrated superior inhibitory activity in comparison to reference compound Vorinostat. Because the compounds with a five-carbon side chain turned out to be the most active, thus, in Series 3 (Table 1, Scheme 2), only derivatives with five-carbon side chain were used.

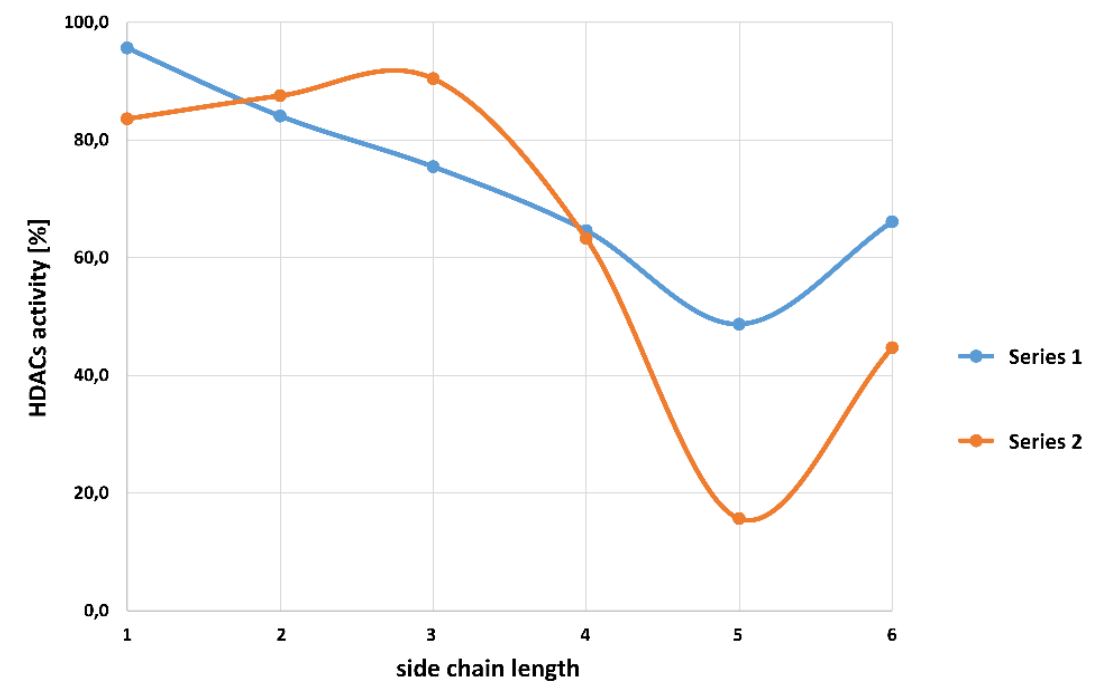

Figure 3. Structure-related activity of Vorinostat derivatives showing the percentage of HDACs activity at $2 \mu \mathrm{M}$ depending on the side chain length.

Table 1. HDACs inhibition of newly synthesized Vorinostat derivatives. For Vorinostat (1) HDACs activity at $2 \mu \mathrm{M}$ was $23.8 \pm 2.2$.

\begin{tabular}{|c|c|c|c|c|c|c|c|}
\hline \multicolumn{8}{|c|}{ Series 1} \\
\hline Compound & $7 a$ & $7 b$ & \multicolumn{2}{|c|}{$7 c$} & $7 d$ & $7 e$ & $7 f$ \\
\hline $\begin{array}{c}\text { HDAC activity } \\
\text { at } 2 \mu \mathrm{M}[\%]\end{array}$ & $95.6 \pm 1.4$ & $84.1 \pm 2.3$ & \multicolumn{2}{|c|}{$75.4 \pm 3.0$} & $64.6 \pm 3.6$ & $48.7 \pm 1.0$ & $66.1 \pm 4.1$ \\
\hline \multicolumn{8}{|c|}{ Series 2} \\
\hline Compound & $7 g$ & $7 \mathrm{~h}$ & \multicolumn{2}{|c|}{$7 \mathbf{i}$} & $7 \mathbf{j}$ & $7 \mathbf{k}$ & 71 \\
\hline $\begin{array}{c}\text { HDAC activity } \\
\text { at } 2 \mu \mathrm{M}[\%]\end{array}$ & $83.6 \pm 4.2$ & $87.5 \pm 1.2$ & \multicolumn{2}{|c|}{$90.4 \pm 1.6$} & $3.3 \pm 0.5$ & $15.7 \pm 1.3$ & $44.7 \pm 4.4$ \\
\hline \multicolumn{8}{|c|}{ Series 3} \\
\hline Compound & $7 \mathrm{~m}$ & $7 n$ & 70 & $7 p$ & $7 r$ & $7 s$ & $7 t$ \\
\hline $\begin{array}{c}\text { HDAC activity } \\
\text { at } 2 \mu \mathrm{M}[\%]\end{array}$ & $72.7 \pm 5.2$ & $68.3 \pm 2.8$ & $64.5 \pm 2.1$ & $21.5 \pm 1.6$ & $31.5 \pm 7.1$ & $35.9 \pm 0.8$ & $19.9 \pm 1.6$ \\
\hline
\end{tabular}




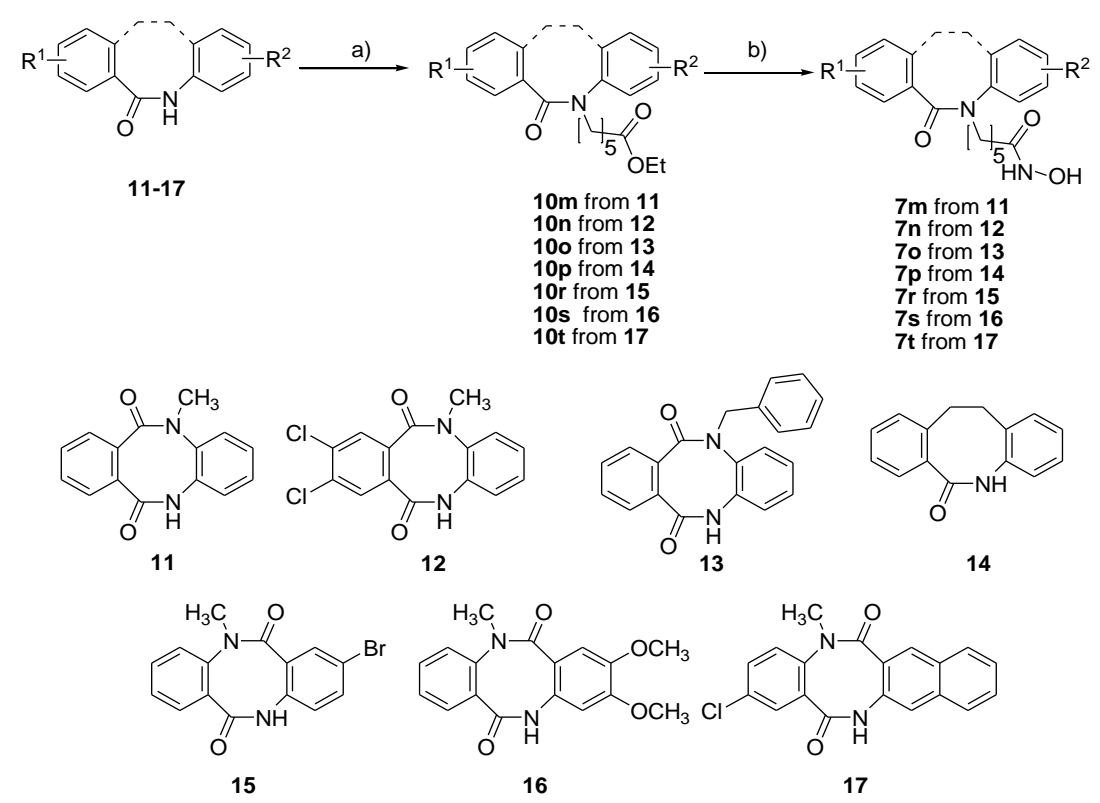

Scheme 2. The synthesis of the Series 3 compounds $7 \mathbf{m}-\mathbf{t}$ : a) $\mathrm{Br}\left(\mathrm{CH}_{2}\right)_{5} \mathrm{COOEt}, \mathrm{NaH}, \mathrm{DMSO}, 18 \mathrm{~h}, \mathrm{rt}$, $\mathrm{R}=\mathrm{Me}, \mathrm{Et} ; \mathrm{b}) \mathrm{NH}_{2} \mathrm{OH} \times \mathrm{H}_{2} \mathrm{O}, \mathrm{THF}, \mathrm{MeOH}, 18 \mathrm{~h}$, rt.

In the next part of our research we decided to synthesize the compounds of Series 3 and to use seven tricyclic 'caps': 5-methyl-5,12-dihydrodibenzo[ $b, f][1,4]$ diazocine-6,11-dione 2,3-dichloro-5-methyl-5,12-dihydrodibenzo[b,f][1,4]diazocine-6,11-dione 5-benzyl-5,12-dihydrodibenzo[b,f][1,4]diazocine-6,11-dione 11,12-dihydrodibenzo[ $b, f]$ azocin-6 $(5 H)$-one 2-bromo-11-methyldibenzo[ $b, f][1,5]$ diazocine-6,12(5H,11H)-dione [96], 2,3-dimethoxy-11-methyldibenzo $[b, f][1,5]$ diazocine- $6,12(5 H, 11 H)$-dione 2-chloro-5-methylbenzo[ $b]$ naphtho[2,3-f][1,5]diazocine-6,14(5H,13H)-dione (Scheme 2). Previously obtained compounds 11-17 were treated with ethyl 6-bromohexanoate in the presence of sodium hydride which resulted in the intermediate products $\mathbf{1 0 m}-\mathbf{t}$. After chromatographic purification and isolation, esters $\mathbf{1 0} \mathbf{m}-\mathbf{t}$ were treated with hydroxylamine hydrate resulting in the final hydroxamic acids $\mathbf{7 m - t}$. Using a standard fluorimetric HDAC inhibition kit (Sigma-Aldrich) to determine the inhibitory potency of the series 3 Vorinostat analogues, we observed that tested the compounds inhibited HDAC activity to a different degree, however, two of them, namely, $7 \mathbf{p}$ and $7 \mathbf{t}$, showed even higher activity than the reference Vorinostat.

Among 19 newly synthesized Vorinostat analogues, IC 50 was determined for the seven most active and promising derivatives: 7e, 7k, 71, 7p-t (Figure 4, Table 2). The lowest values were achieved for compounds $7 \mathbf{k}$ with dibenzo[ $b$,f]azocin-6(5H)-one (9) 'cap' $\left(\mathrm{IC}_{50}=0.183 \mu \mathrm{M}\right), 7 \mathfrak{t}$ with 11,12-dihydrodibenzo[b,f]azocin-6(5H)-one 'cap' (14) (IC 50 $=0.266 \quad \mu \mathrm{M}), \quad$ and $7 \mathbf{p}$ with 2-chloro-5-methylbenzo[ $b]$ naphtho[2,3-f][1,5]diazocine-6,14(5H,13H)-dione 'cap' (17) $\left(\mathrm{IC}_{50}=0.309 \mu \mathrm{M}\right)$. These values exceeded the value obtained for the reference Vorinostat, which inhibited HDAC with $\mathrm{IC}_{50}=0.630 \mu \mathrm{M}$. Tricyclic 'caps' 9, 14 and 17 together with a five-carbon side chain were optimal for the high inhibitory activity of the compounds tested. At the same time, the two derivatives $7 \mathbf{r}$ and $7 \mathbf{s}$, possessing a dibenzo[b,f][1,5]diazocine-6,12(5H,11H)-dione central unit, showed a slightly weaker but still comparable activity to Vorinostat ( $\mathrm{IC}_{50}=0.875 \mu \mathrm{M}$ and $0.914 \mu \mathrm{M}$, respectively.). Compounds 11-13, all based on the 5,12-dihydrodibenzo[ $b, f][1,4]$ diazocine-6,11-dione structure, exhibited very poor or no activity against HDAC homologues. 


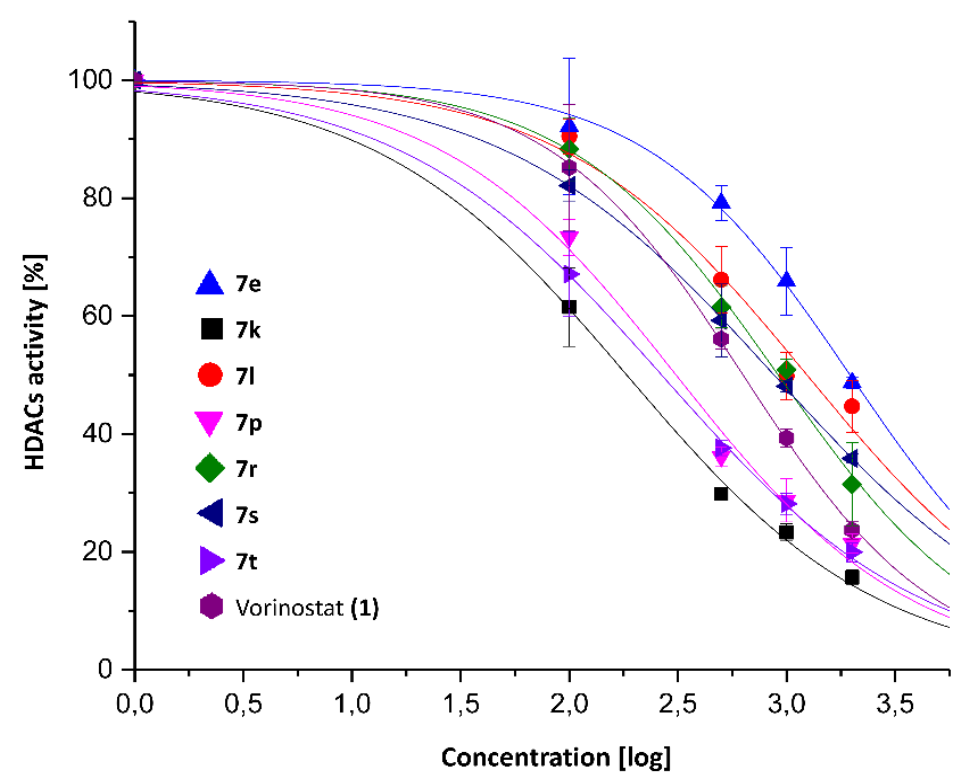

Figure 4. HDACs activity inhibition for the most active compounds.

Table 2. Inhibition of HDAC homologues (HDACs) and HDAC8 activity (IC $50[\mu \mathrm{M}])$ for selected compounds. N/T - no tested.

\begin{tabular}{ccc}
\hline Compound & HDACs & HDAC8 \\
\hline $\mathbf{7 e}$ & $1.959 \pm 0.105$ & $5.67 \pm 0.64$ \\
$\mathbf{7 k}$ & $\mathbf{0 . 1 8 3} \pm \mathbf{0 . 0 1 5}$ & $3.37 \pm 0.33$ \\
$\mathbf{7 1}$ & $1.241 \pm 0.155$ & $\mathrm{~N} / \mathrm{T}$ \\
$\mathbf{7} \mathbf{p}$ & $\mathbf{0 . 3 0 9 \pm 0 . 0 3 5}$ & $3.14 \pm 0.42$ \\
$\mathbf{7 r}$ & $0.914 \pm 0.053$ & $\mathrm{~N} / \mathrm{T}$ \\
$\mathbf{7 s}$ & $0.875 \pm 0.017$ & $\mathrm{~N} / \mathrm{T}$ \\
$\mathbf{7 t}$ & $\mathbf{0 . 2 6 6 \pm 0 . 0 1 4}$ & $1.95 \pm 0.17$ \\
Vorinostat $(\mathbf{1})$ & $0.630 \pm 0.011$ & $1.51 \pm 0.13$ \\
\hline
\end{tabular}

We performed in silico molecular docking which revealed that the HDAC8 homologue is the most promising target for compounds used: $7 \mathbf{e}, 7 \mathbf{k}, 7 \mathbf{p}$ and $7 \mathbf{t}$ (the most significant differences in the interaction pattern between active and inactive compounds along with Vorinostat, see Molecular Modelling section). For this reason, we evaluated the efficacy of the HDAC8 inhibition activity of $7 \mathbf{e}, 7 \mathbf{k}, 7 \mathbf{p}$ and $7 \mathbf{t}$ and Vorinostat as the reference (Table 2). We observed that all tested compounds exhibited a significant inhibitory effect on HDAC 8 . The lowest value, $\mathrm{IC}_{50}=1.51 \pm 0.13 \mu \mathrm{M}$, was obtained for Vorinostat. All new compounds showed comparable, yet slightly lower effect with IC 50 values in the range of $1.95 \pm 0.17 \mu \mathrm{M}$ for $7 \mathrm{t}$ to $5.67 \pm 0.64 \mu \mathrm{M}$ for $7 \mathrm{e}$. Lower IC 50 values obtained for the mixture of HDAC homologues, compared to the IC 50 values for HDAC8 protein may indicate that other HDAC homologues found in the cell lysate are more susceptible to the tested compounds, and could show lower IC 50 , than HDAC8. An important factor that should also be taken into account are the different concentrations of individual HDAC homologues in the cell lysate influencing the total enzymatic activity of the mixture of HDAC homologues.

\subsection{Cytotoxic activity and selectivity index}


For the selection of the most promising cytotoxic agents, all 19 newly synthesized compounds, as well as the reference HDAC inhibitor - Vorinostat, were initially tested on two cancer cell lines: MV4-11 (biphenotypic B myelomonocytic leukemia) and Daudi (Burkitt's lymphoma) (Table 3). Five compounds: $7 \mathbf{k}$ and $\mathbf{7 p - t}$, exhibited IC50 below 1 $\mu \mathrm{M}$, in the range of $0.093 \mu \mathrm{M}(7 \mathrm{t})$ to $0.692 \mu \mathrm{M}(7 \mathrm{~s})$ on MV4-11 and in the range of 0.137 $\mu \mathrm{M}(7 \mathrm{t})$ to $0.944 \mu \mathrm{M}(7 \mathrm{~s})$ on Daudi. In the case of leukemic cell line MV4-11, three out of five compounds $7 \mathbf{k}, 7 \mathbf{p}$ and $7 \mathbf{t}$ showed lower IC50 values than Vorinostat $(0.220,0.200$ and $0.093 \mu \mathrm{M}$, respectively, versus $0.636 \mu \mathrm{M})$. Again, with the lymphoma cell line Daudi, 7k, 7p, and 7t showed lower (or comparable) IC 50 values than Vorinostat (0.460, 0.318 , and $0.137 \mu \mathrm{M}$, respectively, versus $0.493 \mu \mathrm{M}$ ). The most potent cytotoxic compounds, $7 \mathbf{k}$ and $\mathbf{7 p - t}$, were further evaluated for their cytotoxic effect on two solid tumor cancer cell lines: A549 (lung carcinoma) and MCF-7 (breast adenocarcinoma). To determine the selectivity of the tested compounds, one reference cell line Balb/3T3 (mouse fibroblasts), derived from a non-cancerous cell line was also used. In the case of A549 cell line, two compounds: $7 \mathbf{t}$ and $7 \mathbf{p}$ showed lower IC 50 values than Vorinostat $(1.05,1.21$, respectively, versus $1.64 \mu \mathrm{M})$. Similarly, in the case of MCF-7 cell line two compounds: $7 \mathbf{t}$ and $7 \mathbf{p}$ showed lower (or comparable) IC 50 values than Vorinostat $(0.368,0.661$, respectively, versus $0.685 \mu \mathrm{M})$. Compounds $7 \mathbf{p}$ and $7 \mathbf{t}$ exhibited the strongest cytotoxic effect on cancer cell lines but the observed cytotoxicity also extended to the reference normal fibroblasts cell line. The two most active compounds $7 \mathbf{t}$ and $7 \mathbf{p}$ were also more toxic to Balb/3T3 than Vorinostat $(0.69,1.04$, respectively, versus $1.42 \mu \mathrm{M})$.

Table 3. IC $\mathrm{C}_{50}[\mu \mathrm{M}]$ of vorinostat derivatives based on the survival of non-cancerous (Balb/3T3) and cancerous (MV4-11, Daudi, MCF-7 and A549) cells after $72 \mathrm{~h}$ of treatment. N/T - no tested.

\begin{tabular}{|c|c|c|c|c|c|c|}
\hline & \multirow{2}{*}{ Compound } & \multicolumn{5}{|c|}{$\mathrm{IC}_{50}[\mu \mathrm{M}]$} \\
\hline \multirow{7}{*}{. } & & MV4-11 & Daudi & A549 & MCF-7 & Balb/3T3 \\
\hline & $7 a$ & $>50.00$ & $>50.00$ & $\mathrm{~N} / \mathrm{T}$ & $\mathrm{N} / \mathrm{T}$ & $\mathrm{N} / \mathrm{T}$ \\
\hline & $7 \mathrm{~b}$ & $>50.00$ & $>50.00$ & $\mathrm{~N} / \mathrm{T}$ & $\mathrm{N} / \mathrm{T}$ & $\mathrm{N} / \mathrm{T}$ \\
\hline & $7 c$ & $>50.00$ & $>50.00$ & $\mathrm{~N} / \mathrm{T}$ & $\mathrm{N} / \mathrm{T}$ & $\mathrm{N} / \mathrm{T}$ \\
\hline & $7 d$ & $7.58 \pm 2.50$ & $9.6 \pm 2.10$ & $\mathrm{~N} / \mathrm{T}$ & $\mathrm{N} / \mathrm{T}$ & $\mathrm{N} / \mathrm{T}$ \\
\hline & $7 e$ & $2.33 \pm 0.64$ & $3.03 \pm 0.55$ & $\mathrm{~N} / \mathrm{T}$ & $\mathrm{N} / \mathrm{T}$ & $\mathrm{N} / \mathrm{T}$ \\
\hline & $7 f$ & $4.45 \pm 0.34$ & $4.83 \pm 1.96$ & $\mathrm{~N} / \mathrm{T}$ & $\mathrm{N} / \mathrm{T}$ & $\mathrm{N} / \mathrm{T}$ \\
\hline \multirow{6}{*}{ 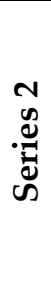 } & $7 g$ & $33.97 \pm 0.75$ & $17.31 \pm 6.2$ & $\mathrm{~N} / \mathrm{T}$ & $\mathrm{N} / \mathrm{T}$ & $\mathrm{N} / \mathrm{T}$ \\
\hline & $7 \mathrm{~h}$ & $>50.00$ & $32.62 \pm 4.78$ & $\mathrm{~N} / \mathrm{T}$ & $\mathrm{N} / \mathrm{T}$ & $\mathrm{N} / \mathrm{T}$ \\
\hline & $7 \mathbf{i}$ & $>50.00$ & $>50.00$ & $\mathrm{~N} / \mathrm{T}$ & $\mathrm{N} / \mathrm{T}$ & $\mathrm{N} / \mathrm{T}$ \\
\hline & $7 \mathbf{j}$ & $5.30 \pm 1.36$ & $3.47 \pm 0.66$ & $\mathrm{~N} / \mathrm{T}$ & $\mathrm{N} / \mathrm{T}$ & $\mathrm{N} / \mathrm{T}$ \\
\hline & $7 \mathbf{k}$ & $0.220 \pm 0.021$ & $0.460 \pm 0.122$ & $1.27 \pm 0.42$ & $0.618 \pm 0.095$ & $1.28 \pm 0.15$ \\
\hline & 71 & $1.57 \pm 0.12$ & $1.44 \pm 0.61$ & $\mathrm{~N} / \mathrm{T}$ & $\mathrm{N} / \mathrm{T}$ & $\mathrm{N} / \mathrm{T}$ \\
\hline \multirow{8}{*}{ 趈 } & $7 \mathrm{~m}$ & $4.45 \pm 0.96$ & $5.09 \pm 0.3$ & $\mathrm{~N} / \mathrm{T}$ & $\mathrm{N} / \mathrm{T}$ & $\mathrm{N} / \mathrm{T}$ \\
\hline & $7 n$ & $2.85 \pm 0.34$ & $2.56 \pm 0.98$ & $\mathrm{~N} / \mathrm{T}$ & $\mathrm{N} / \mathrm{T}$ & $\mathrm{N} / \mathrm{T}$ \\
\hline & 70 & $3.55 \pm 0.75$ & $3.52 \pm 0.80$ & $\mathrm{~N} / \mathrm{T}$ & $\mathrm{N} / \mathrm{T}$ & $\mathrm{N} / \mathrm{T}$ \\
\hline & $7 p$ & $0.200 \pm 0.073$ & $0.318 \pm 0.098$ & $1.21 \pm 0.24$ & $0.661 \pm 0.12$ & $1.04 \pm 0.28$ \\
\hline & $7 r$ & $0.603 \pm 0.132$ & $0.785 \pm 0.246$ & $4.61 \pm 0.38$ & $2.72 \pm 0.57$ & $3.37 \pm 0.87$ \\
\hline & $7 \mathrm{~s}$ & $0.692 \pm 0.110$ & $0.944 \pm 0.167$ & $17.96 \pm 5.77$ & $4.24 \pm 1.03$ & $12.04 \pm 5.9$ \\
\hline & $7 t$ & $0.093 \pm 0.009$ & $0.137 \pm 0.04$ & $1.05 \pm 0.07$ & $0.368 \pm 0.015$ & $0.69 \pm 0.05$ \\
\hline & Vorinostat (1) & $0.636 \pm 0.092$ & $0.493 \pm 0.093$ & $1.64 \pm 0.32$ & $0.685 \pm 0.06$ & $1.42 \pm 0.23$ \\
\hline
\end{tabular}

The obtained results showed a close correlation between HDAC inhibition and the cytotoxic effect of the tested compounds. The three most potent HDAC inhibitors: $\mathbf{7 k}$, $7 \mathbf{p}$, and $7 \mathrm{t}$ also showed the strongest cytotoxic effect on tested cell lines. 
To determine the selectivity of tested compounds, we compared the cytotoxic effect observed for cancer cell lines (MV4-11, Daudi, A549, MCF7) and the reference line Balb/3T3. The selectivity indexes were calculated for the five most active compounds $(7 \mathbf{k}, 7 \mathbf{p}-\mathbf{7 t})$ and Vorinostat (Table 4). In all cases, the selectivity index of Vorinostat never exceeded the value of 3 and varied from 2.88 (Daudi) to 0.87 (A549). The highest selectivity indexes were obtained for compounds $7 \mathrm{~s}$ (17.4 for MV4-11 and 12.75 for Daudi) and $7 \mathfrak{t}$ (7.42 for MV4-11 and 5.05 for Daudi). The remaining compounds $7 \mathbf{k}, 7 \mathbf{p}$ and $7 \mathbf{r}$ (except of 7k and Daudi) also possessed higher selectivity indexes for MV4-11 and Daudi, than Vorinostat. We observed that while Vorinostat is slightly more selective for Daudi (lymphoma) than for MV4-11 (leukemia), our compounds exhibited better selectivity toward MV4-11 (leukemia) than for Daudi (lymphoma). In general, Vorinostat, as well as the newly synthesized compounds, exhibited relatively low selectivity toward solid tumor cancer cell lines (A549 and MCF-7) as compared to BALB/3T3 reference line.

Table 4. Selectivity index (IC 50 of normal vs cancer cells). SI $>1.0$ indicates a compound of greater activity against cancer cells and lower cytotoxicity on normal cells.

\begin{tabular}{|c|c|c|c|c|}
\hline \multicolumn{4}{|c|}{ Compound MV4-11Daudi A549 } & MCF-7 \\
\hline $7 \mathrm{k}$ & 5.82 & 2.78 & 1.01 & 2.07 \\
\hline $7 p$ & 5.20 & 3.27 & 0.86 & 1.57 \\
\hline $7 \mathbf{r}$ & 5.59 & 4.29 & 0.73 & 1.24 \\
\hline $7 \mathrm{~s}$ & 17.4 & 12.75 & 0.67 & 2.84 \\
\hline $7 \mathrm{t}$ & 7.42 & 5.04 & 0.66 & 1.88 \\
\hline Vorinostat (1) & 2.23 & 2.88 & 0.87 & 2.07 \\
\hline
\end{tabular}

\subsection{Molecular modelling}

To define and elucidate the binding modes of the synthetized compounds, molecular docking of these compounds in the active site of histone deacetylases 1, 2, 3, 4, 6, 7 and 8 (HDACs) was performed. Among all HDACs' structures stored in PDB only structures with the co-crystalized ligand and binding pocket exposed to the solvent were taken into account. Structures which were co-crystalized with Vorinostat and had the best resolution were preferred. Finally, one crystal structure per HDAC was selected (Table 5) and prepared in Protein Preparation Wizard [100-101], under default settings (coordination of zinc ion was set as constraint, centered on ligand). The three dimensional structure, conformation and protonation states of the evaluated compounds were generated by LigPrep (at pH 7.4) and Epik [101-103]. Finally, Glide [101-106] was used for docking each compound to every protein crystal. Each pose was ranked according to docking score (the lower value, the better), and the best scored pose per compound was chosen for further analysis.

Table 5. PDBids of crystals used in docking studies

\begin{tabular}{|c|c|c|c|}
\hline Histone diacetylase & PDBid & Ligand & Resolution [Å] \\
\hline HDAC1 & $5 \mathrm{ICN}$ & GAXRH (peptide) & 3.30 \\
\hline HDAC2 & $4 \mathrm{LXZ}$ & Vorinostat & 1.85 \\
\hline HDAC3 & $4 \mathrm{~A} 69$ & IOP & 2.06 \\
\hline HDAC4 & 2VQM & HA3 & 1.80 \\
\hline HDAC6 & 5EDU & Trichostatin A & 2.79 \\
\hline HDAC7 & $3 \mathrm{COZ}$ & Vorinostat & 2.10 \\
\hline HDAC8 & $1 \mathrm{~T} 69$ & Vorinostat & 2.91 \\
\hline
\end{tabular}

The majority of the evaluated compounds were docked to six out of seven HDAC types. Only HDAC3 was unable to form protein-ligand complex with the synthetized compounds and only Vorinostat was docked to this crystal. Binding modes for these 
evaluated compounds in binding pockets of HDACs 1, 3 and 7 were both very similar for all docked compounds. Active compounds (7e, $7 \mathbf{k}, \mathbf{7 t}$ and $\mathbf{7 p}$ ) docked to the HDAC1 did not have optimized geometry of zinc ion coordination despite the fact that they had very low (below -8 , see Table S1, SI file) values of the scoring function. Both, active and inactive compounds share the same interaction pattern, involving amino acid residues H180, G151 and some of them even F208. In the binding mode of Vorinostat the additional interaction with residue D101 can be observed, but there is no hydrogen bond with H180 (Figure 5A). Docking results for HDAC3 structure allowed for distinguishing between active from inactive compounds using scoring function (four active compounds are in the five top scoring compounds; values below -6, see Table S1, SI file), but the interaction profile of active and inactive compounds were very similar. Almost all compounds interacted with the zinc ion and residue G151, while contacts with other residues were rarely formed. Nevertheless, the hydrophobic cap of inactive compounds (e.g. for $7 \mathbf{i}$ ) had a somewhat different orientation in the binding pocket than for active ones. (Figure 5B). The interaction pattern for Vorinostat with the HDAC3 binding pocket was extremely poor - the compound interacted only with the zinc ion. For HDAC7 binding poses did not allow for separating active from inactive compounds. Almost all compounds interacted with the zinc ion and residue G151, but there were no specific interactions observed for active compounds only (Figure 5C). In contrast, the binding mode of active compounds was different than inactive compounds for HDACs 2, 6 and 8. In the case of HDAC2, active compounds created hydrogen bonds with residues Y306 and Y207. Moreover, they interacted via $\pi-\pi$ stacking interaction with F208 (Figure 5D). These interactions were not commonly observed neither for inactive compounds nor for Vorinostat. Similar observations can be seen for HDAC6. Active compounds, except commonly observed interactions with residues Y306 and H143, interacted with residue H180 and formed at least one hydrogen bond with an aromatic cluster, i.e. F207 and F208 (Figure 5E). This interaction with F207 or F208 enriches the interaction profile which characterizes Vorinostat in HDAC6 binding mode. In HDAC8 crystal structures Vorinistat interacts only with zinc ion and residue H143 and this interaction profile was shared by inactive compounds. Active compounds showed additional interactions with Y306 and F207 (hydrogen bonds or $\pi-\pi$ stacking, Figure 5F), which were not observed for the remaining compounds. 


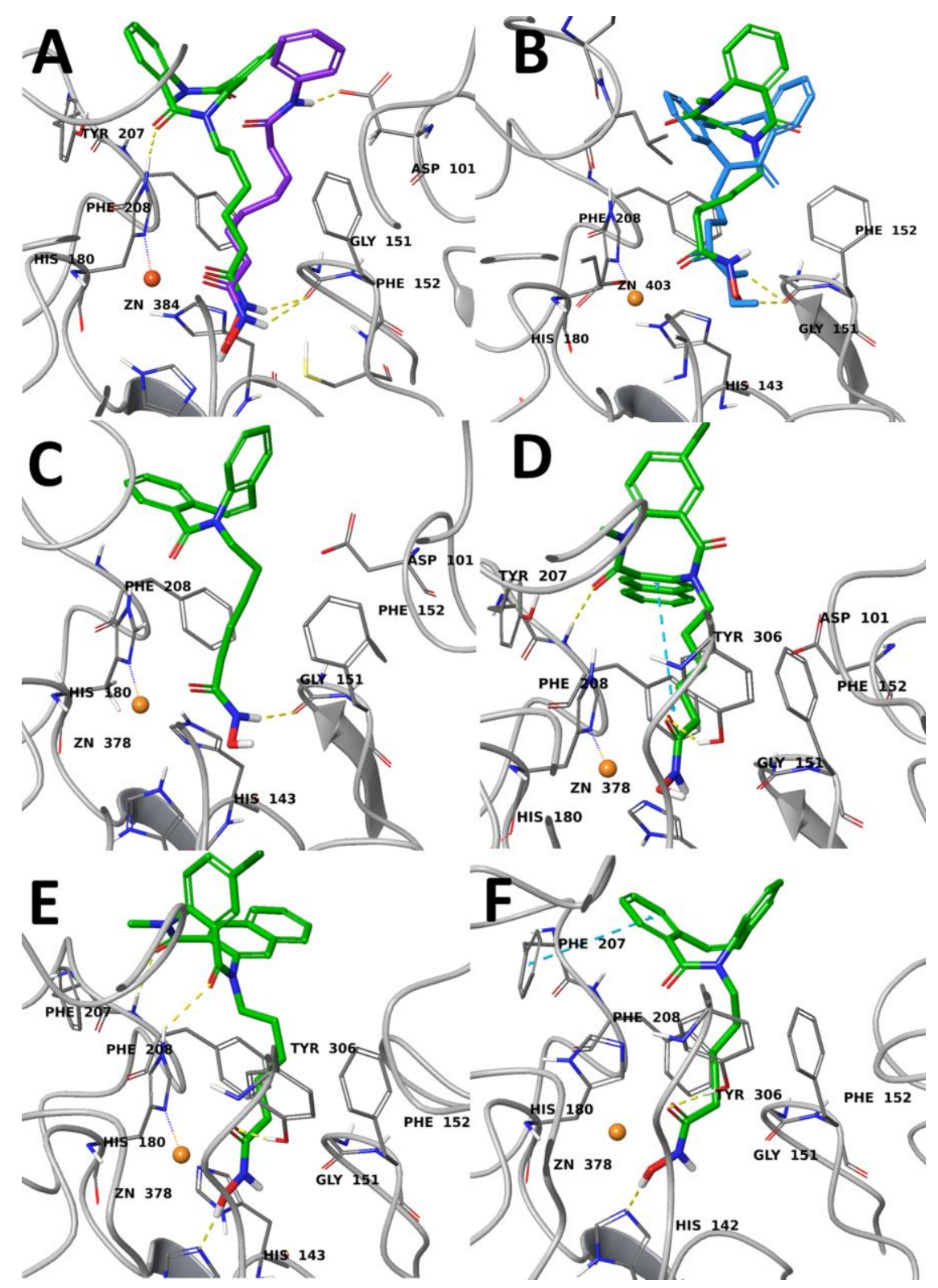

Figure 5. Representative L-R virtual complexes of (a) 7e (rendered in green) and Vorinostat (violet) in binding pocket of HDAC1(PDBid: $5 \mathrm{ICN}$ ), (b) 7e (green) and 7i (blue) in binding pocket of HDAC4(PDBid: 2VQM), (c) 7k (green) in binding pocket of HDAC7 (PDBid: 3C0Z), (d) 7t (green) in binding pocket of HDAC2 (PDBid: 4LXZ), (e) $7 \mathfrak{t}$ (green) in binding pocket of HDAC6 (PDBid: 5EDU) and (f) 7k (green) in binding pocket of HDAC8 (PDBid: 1T69). Yellow dashed lines indicate hydrogen bonds, whereas blue dashed lines indicate aromatic interactions. Zinc ion is rendered in orange.

\section{Conclusions}

We synthesized 19 novel HDAC inhibitors based on the Vorinostat structure. The introduction of a larger tricyclic hydrophobic 'cap' to the structure of Vorinostat in the place of the phenyl group was beneficial for biological properties and allowed for the development of compounds with improved HDAC inhibition, stronger cytotoxic effect and higher selectivity against leukemia and lymphoma cell lines. We observed that the enlargement of the hydrophobic 'cap' from a single benzene ring to a heterocyclic three-ring system forced a shortening of the length of the linker connecting the hydrophobic group to the hydroxamic acid residue. We also observed that the biological properties of the tested compounds (HDAC inhibition and the resulting cytotoxic effect) strongly depend on the tricyclic core used. We concluded that for optimal biological 
properties, an appropriate balance between the size/type of the hydrophobic group and the length of the side chain, terminated in the hydroxamic acid group, is necessary. We also observed a strong correlation between HDAC inhibition and cytotoxicity, so we concluded that HDAC inhibition should be the main factor responsible for the observed biological properties of the developed compounds. The tested HDAC inhibitors exhibited a stronger and more selective cytotoxic effect against MV4-11 and Daudi, while the cell lines derived from solid tumors and mouse fibroblasts proved to be much less sensitive to our compounds. Thus, we expect that they can find application as selective compounds against leukemias and lymphomas.

\section{Supplementary Materials: The following are available online at}

Author Contributions: Design, conception and writing were performed by B.B., A.M., D.G., E.G.; biological data analysis and determination of HDACs activity were performed by D.G., E.G.; cytotoxicity screening was conducted by M.Ś, J.W.; synthesis, purification and structure elucidation were performed by B.B.; recording NMR spectra was performed by M.K.D.; in silico modeling was performed by D.W.; All authors reviewed and approved the final version. All authors have read and agreed to the published version of the manuscript.

Funding: This work was supported by the MNiSW grant (Diamentowy Grant V 0072/DIA/2016/45, B.B.). D.W. was supported by the Polish National Centre for Research and Development grant LIDER/37/0137/L-9/17/NCBR/2018.

Informed Consent Statement: Not applicable.

Data Availability Statement: Data is contained within the article or Supplementary Material.

Acknowledgments: We thank Jacek Olędzki for recording the ES-MS spectra.

Conflicts of Interest: The authors declare no conflict of interest. The funders had no role in the design of the study; in the collection, analyses, or interpretation of data; in the writing of the manuscript, or in the decision to publish the results.

\section{References}

[1] Park, S.-Y,; Kim, J.-S.; A short guide to histone deacetylases including recent progress on class II enzymes. Exp. Mol. Med. 2020, 52, 204-212. doi: 10.1038/s12276-020-0382-4;

[2] Seto, E.; Yoshida, M. Erasers of histone acetylation: The histone deacetylase enzymes. Cold Spring Harb. Perspect. Biol. 2014, 6, a018713. doi: 10.1101/cshperspect.a018713;

[3] Gallinari, P.; Di Marco, S.; Jones, P.; Pallaoro, M.; Steinkühler, C.; HDACs, histone deacetylation and gene transcription: from molecular biology to cancer therapeutics. Cell Res. 2007, 17, 195-211. doi: 10.1038/sj.cr.7310149;

[4] Lombardi, P. M.; Cole, K. E.; Dowling, D. P.; Christianson, D. W.; Structure, mechanism, and inhibition of histone deacetylases and related metalloenzymes. Curr. Opin. Struct. Biol. 2011, 21, 735-743. doi: 10.1016/j.sbi.2011.08.004;

[5] Haberland, M.; Montgomery, R. L.; Olson, E. N.; The many roles of histone deacetylases in development and physiology: implications for disease and therapy. Nat. Rev. Genet. 2009, 10, 32-42. doi: 10.1038/nrg2485;

[6] Seidel, C.; Schnekenburger, M.; Dicato, M.; Diederich, M.; Histone deacetylase 6 in health and disease. Epigenomics 2015, 7, 103-118. doi: 10.2217/epi.14.69;

[7] Zwergel, C.; Stazi, G.; Valente, S.; Mai, A.; Histone deacetylase inhibitors: Updated studies in various epigenetic-related diseases. J. Clin. Epigenet. 2016, 2, 7. doi: 10.21767/2472-1158.100015;

[8] Eckschlager, T.; Plch, J.; Stiborova, M.; Hrabeta, J.; Histone deacetylase inhibitors as anticancer drugs. Int. J. Mol. Sci. 2017, 18, 1414. doi: 10.3390/ijms18071414;

[9] Hassel, K. N.; Histone deacetylases and their inhibitors in cancer epigenetics. Diseases 2019, 7, 57; doi: 10.3390/diseases7040057;

[10] Zhao, C.; Dong, H.; Xu, Q.; Zhang, Y.; Histone deacetylase (HDAC) inhibitors in cancer: a patent review (2017-present). Expert Opin. Ther. Pat. 2020, 20, 263-374. doi: 10.1080/13543776.2020.1725470;

[11] Chen, I.; Sethy, B.; Liou, J.-P. Recent update of HDAC inhibitors in lymphoma. Front. Cell Dev. Biol. 2020, 8, 576391. doi: 10.3389/fcell.2020.576391;

[12] Sinhg, A. K.; Bishayee, A.; Pandey, A. K.; Targeting histone deacetylases with natural and synthetic agents: An emerging anticancer strategy. Nutrients 2018, 10, 731. doi: 10.3390/nu10060731;

[13] West, A. C.; Johnstone, R. W.; New and emerging HDAC inhibitors for cancer treatment. J. Clin. Invest. 2014, 124, 30-39. doi: 10.1172/JCI69738; 
[14] Matsui, M.; Terasawa, K.; Kajikuri, J.; Kito, H.; Endo, K.; Jaikhan, P.; Suzuki, T.; Ohya, S.; Histone deacetylases enhance Ca2+-activated $\mathrm{K}+$ shannel KCa3.1 expression in murine inflammatory CD4+ T cells. Int. J. Mol. Sci. 2018, 19, 2942;. doi: 10.3390/ijms19102942;

[15] Delgado, F. G.; Cardenas, P.; Castellanos, J. E.; Valproic acid downregulates cytokine expression in human macrophages infected with Dengue virus. Diseases 2018, 6, 59; doi: 10.3390/diseases6030059;

[16] Jan, J.-S.; Chou, Y.-C.; Cheng, Y.-W.; Chen, C.-K.; Huang, W.-J.; Hsiao, G.; The novel HDAC8 inhibitor WK2-16 attenuates lipopolysaccharide-activated matrix metalloproteinase-9 expression in human monocytic cells and improves hypercytokinemia in vivo. Int. J. Mol. Sci. 2017, 18, 1394. doi: 10.3390/ijms18071394;

[17] Pham, T. X.; Park, Y.-K.; Lee, J.-Y.; Anti-inflammatory effects of Spirulina platensis extract via the modulation of histone deacetylases. Nutrients 2016, 8, 381. doi: 10.3390/nu8060381;

[18] Gatla, H. R.; Muniraj, N.; Thevkar, P.; Yavvari, S.; Sukhavasi, S.; Makena, M. R.; Regulation of chemokines and cytokines by histone deacetylases and an update on histone decetylase inhibitors in human diseases. Int. J. Mol. Sci. 2019, 20, 1110. doi: 10.3390/ijms20051110;

[19] Araki, Y.; Mimura, T.; The Histone modification code in the pathogenesis of autoimmune diseases. Mediators Inflamm. 2017, 2017, 2608605. doi: 10.1155/2017/2608605;

[20] Lyu, X.; Hu, M.; Peng, J.; Zhang, X.; Sanders, Y. Y.; HDAC inhibitors as antifibrotic drugs in cardiac and pulmonary fibrosis. Ther. Adv. Chronic Dis. 2019, 10, 2040622319862697. doi: 10.1177/2040622319862697;

[21] Yooh, S.; Kang, G.; Eom, G. H.; HDAC inhibitors: Therapeutic potential in fibrosis-associated human diseases. Int. J. Mol. Sci. 2019, 20, 1329. doi: 10.3390/ijms20061329;

[22] Suh, S. H.; Choi, H. S.; Kim, C. S.; Kim, I. J.; Cha, H.; Cho, J. M.; Ma, S. K.; Kim, S. W.; Bae, E. H. CG200745, a novel HDAC inhibitor, attenuates kidney fibrosis in a murine model of alport syndrome. Int. J. Mol. Sci. 2020, 21, 1473. doi: 10.3390/ijms21041473;

[23] Pardo-Jimenez, V.; Navarrete-Encina, P.; Diaz-Araya, G. Synthesis and biological evaluation of novel thiazolyl-coumarin derivatives as potent histone deacetylase inhibitors with antifibrotic activity. Molecules 2019, 24, 739. doi: 10.3390/molecules24040739;

[24] Nural-Guvener, H.; Zakharova, L.; Feehery, L.; Sljukic, S.; Gaballa, M.; Anti-fibrotic effects of class I HDAC inhibitor, Mocetinostat is associated with IL-6/Stat3 signaling in ischemic heart failure. Int. J. Mol. Sci. 2015, 16, 11482-11499. doi: 10.3390/ijms160511482;

[25] Hockly, E.; Richon, V. M.; Woodman, B.; Smith, D. L.; Zhou, X.; Rosa, E.; Sathasivam, K.; Ghazi-Noori, S.; Mahal, A.; Lowden, P. A. S.; Steffan, J. S.; Marsh, J. L.; Thompson, L. M.; Lewis, C. M.; Marks, P. A.; Bates, G. P.; Suberoylanilide hydroxamic acid, a histone deacetylase inhibitor, ameliorates motor deficits in a mouse model of Huntington's disease. Proc. Natl. Acad. Sci. U.S.A. 2003, 100, 2041-2046. doi: 10.1073/pnas.0437870100;

[26] Mielcarek, M.; Landles, C.; Weiss, A.; Bradaia, A.; Seredina, T.; Inuabasi, L.; Osborne, G. .; Wadel, K.; Touller, C.; Butler, R.; Robertson, J.; Franklin, S. A.; Smith, D. L.; Park, L.; Marks, P. A. Wanker, E. E.; Olson, E. N.; Luthi-Carter, R.; van der Putten, H.; Beaumont, V.; Bates, G. P.; HDAC4 reduction: A novel therapeutic strategy to target cytoplasmic huntingtin and a meliorate neurodegeneration. PLoS Biol. 2013, 11, e1001717. doi: 10.1371/journal.pbio.1001717;

[27] D'Mello, S. R.; Histone deacetylases as targets for the treatment of human neurodegenerative diseases. Drug News Perspect. 2009, 22, 513-524. doi: 10.1358/dnp.2009.9.1428871;

[28] Jeong, H.; Shin, S.; Lee, J.-S.; Lee, S. H.; BAik, J.-H.; Lim, S.; Kim, Y. K.; Pan-HDAC inhibitors promote tau aggregation by increasing the level of acetylated tau. Int. J. Mol. Sci. 2019, 20, 4283. doi: 10.3390/ijms20174283;

[29] Mohseni, J.; Zabidi-Hussin, Z. A. M. H.; Sasongko, T. H.; Histone deacetylase inhibitors as potential treatment for spinal muscular atrophy. Genet. Mol. Biol. 2013, 36, 299-307. doi: 10.1590/S1415-47572013000300001;

[30] Xu, C.; Soragni, E.; Jacques, V.; Rusche, J. R.; Gottesfeld, J. M.; Improved histone deacetylase inhibitors as therapeutics for the neurodegenerative disease Friedreich's ataxia: A new synthetic route. Pharmaceuticals 2011, 4, 1578-1590. doi: 10.3390/ph4121578;

[31] Zwinderman, M. R. H.; de Weerd, S.; Dekker, F. J.; Targeting HDAC complexes in asthma and COPD. Epigenomes 2019, 3, 19. doi: 10.3390/epigenomes3030019;

[32] Sharma, C.; Oh, Y. J.; Park, B.; Lee, S.; Jeong, C.-H.; Lee, S.; Seo, J. H.; Seo, Y. H.; Development of thiazolidinedione-based HDAC6 inhibitors to overcome methamphetamine addiction. Int. J. Mol. Sci. 2019, 20, 6213. doi: 10.3390/ijms20246213;

[33] Habibian, J.; Ferguson, B. S.; The crosstalk between acetylation and phosphorylation: Emerging new roles for HDAC inhibitors in the heart. Int. J. Mol. Sci. 2019, 20, 102. doi: 10.3390/ijms20010102;

[34] Evans, L. W.; Ferguson, B. S.; Food bioactive HDAC inhibitors in the epigenetic regulation of heart failure. Nutrients 2018, 10, 1120. doi: 10.3390/nu10081120;

[35] Schiattarella, G. G.; Sannino, A.; Toscano, E.; Cattaneo, F.; Trimarco, B.; Esposito, G.; Perrino, C. Cardiovascular effects of histone deacetylase inhibitors epigenetic therapies: Systematic review of 62 studies and new hypotheses for future research. Int. J. Cardiol. 2016, 219, 396-403. doi: 10.1016/j.ijcard.2016.06.012;

[36] Cho, H. M.; Seok, Y. M.; Lee, H. A.; Song, M.; Kim, I.; Repression of transcriptional activity of forkhead box O1 by histone deacetylase inhibitors ameliorates hyperglycemia in type 2 diabetic rats. Int. J. Mol. Sci. 2018, 19, 102. doi: 10.3390/ijms19113539;

[37] Bocchi, L.; Motta, B. M.; Savi, M.; Vilella, R.; Meraviglia, V.; Rizzi, F.; Galati, S.; Buschini, A.; Lazzaretti, M.; Pramstaller, P. P.; Rossini, A.; Stilli, D. Int. J. Mol. Sci. 2019, 20, 1973. doi: 10.3390/ijms20081873; 
[38] Martinez-Pacheco, H.; Picazo, O.; Lopez-Torres, A.; Morin, J.-P,; Castro-Cerritos, K. V.; Zepeda, R. C.; Roldán-Roldán, G.; Biochemical and behavioral characterization of IN14, a new inhibitor of HDACs with antidepressant-like properties. Biomolecules 2020, 10, 299. doi: 10.3390/biom10020299;

[39] McIntyre, R. L.; Daniels, E. G.; Molenaars, M.; Houtkooper, R. H.; Janssens, G. E. From molecular promise to preclinical results: HDAC inhibitors in the race for healthy aging drugs. EMBO Mol. Med. 2019, 11, e9854. doi: 10.15252/emmm.201809854;

[40] Herbein, G.; Wendling, D.; Histone deacetylases in viral infections. Clin. Epigenet. 2010, 1, 13-24. doi: 10.1007/s13148-010-0003-5;

[41] Zhao, F.; Liu, N.; Zhan, P.; Liu, X. Repurposing of HDAC inhibitors toward anti-hepatitis C virus drug discovery: teaching an old dog new tricks. Future Med. Chem. 2015, 7, 1367-1371. doi: 10.4155/fmc.15.76;

[42] Lu, C.-Y.; Chang, Y.-C.; Hua, C.-H.; Chuang, C.; Huang, S.-H.; Kung, S.-H.; Hour, M.-J.; Lin, C.-W.; Tubacin, an HDAC6 selective inhibitor, reduces the replication of the japanese encephalitis virus via the decrease of viral RNA synthesis. Int. J. Mol. Sci. 2017, 18, 954. doi: 10.3390/ijms18050954;

[43] Yedery, R. D.; Jerse, A. E.; Augmentation of cationic antimicrobial peptide production with histone deacetylase inhibitors as a novel epigenetic therapy for bacterial infections. Antibiotics 2015, 4, 44-61. doi: 10.3390/antibiotics4010044;

[44] Cuperlovic-Culf, M.; Culf, A. S.; Role of histone deacetylases in fungal phytopathogenesis: A review. Int. J. Mod. Bot. 2014, 4, 48-50. doi: 10.5923/j.ijmb.20140402.03;

[45] Shanmugam, G.; Kim, T.; Jeon, J. In silico identification of potential inhibitor against a fungal histone deacetylase, RPD3 from Magnaporthe oryzae. Molecules 2019, 24, 2075. doi: 10.3390/molecules24112075;

[46] de Souza, W.; Zuma, A. A.; Histone deacetylases as targets for antitrypanosomal drugs. Future Sci. OA 2018,4 , FSO325. doi: 10.4155/fsoa-2018-0037;

[47] Loeuillet, C.; Touquet, B.; Guichou, J.-F.; Labesse, G.; Sereno, D.; A tiny change makes a big difference in the anti-parasitic activities of an HDAC inhibitor. Int. J. Mol. Sci. 2019, 20, 2973. doi: 10.3390/ijms20122973;

[48] Simoben, C. V.; Robaa, D.; Chakrabarti, A.; Schmidtkunz, K.; Marek, M.; Lancelot, J.; Kannan, S.; Melesina, J.; Shaik, T. B.; Pierce, R. J.; Romier, C.; Jung, M.; Sippl, W.; A novel class of Schistosoma mansoni histone deacetylase 8 (HDAC8) inhibitors identified by structure-based virtual screening and in vitro testing, Molecules 2018, 23, 566. doi: 10.3390/molecules23030566;

[49] Yelton, C. J.; Ray, S. K.; Histone deacetylase enzymes and selective histone deacetylase inhibitors for antitumor effects and enhancement of antitumor immunity in glioblastoma. Neuroimmunol Neuroinflammation 2018, 5, 46. doi: 10.20517/2347-8659.2018.58;

[50] Gao, X.; Shen, L.; Li, X.; Liu, J. Efficacy and toxicity of histone deacetylase inhibitors in relapsed/refractory multiple myeloma: Systematic review and meta-analysis of clinical trials. Exp. Ther. Med. 2019, 18, 1057-1068. doi: 10.3892/etm.2019.7704;

[51] Tandon, N,; Ramakrishnan, V.; Kumar, S. K.; Clinical use and applications of histone deacetylase inhibitors in multiple myeloma. Clin. Pharmacol. 2016, 8, 35-44. doi: 10.2147/CPAA.S94021;

[52] Imai, Y.; Hirano, M.; Kobayashi, M.; Futami, M. Tojo, A.; HDAC inhibitors exert anti-myeloma effects through multiple modes of Action. Cancers 2019, 11, 475. doi: 10.3390/cancers11040475;

[53] Zhang, Q.; Wang, S.; Chen, J.; Yu, Z.; Histone deacetylases (HDACs) guided novel therapies for T-cell lymphomas. Int. J. Med. Sci. 2019, 16, 424-442. doi: 10.7150/ijms.30154;

[54] Damaskos, C.; Valsami, S.; Kontos, M.; Spartalis, E.; Kalampokas, T.; Kalampokas, E.; Anthanasiou, A.; Moris, D.; Daskalopoulou, A.; Davakis, S.; Tsourouflis, G.; Kontzoglou, K.; Perrea, D.; Nikiteas, N.; Dimitroulis, D.; Histone deacetylase inhibitors: An attractive therapeutic strategy against breast cancer. Anticancer Res. 2017, 37, 35-46. doi: 10.21873/anticanres.11286;

[55] San José-Enriz, E.; Gimenez-Camino, N.; Agirre, X.; Prosper, F.; HDAC inhibitors in acute myeloid leukemia. Cancers 2019, 11, 1794. doi: 10.3390/cancers11111794;

[56] Losson, H.; Schnekenburger, M. Dicato, M.; Diederich, M.; HDAC6 - An emerging target against chronic myeloid leukemia? Cancers 2020, 12, 318. doi: 10.3390/cancers12020318;

[57] Cosenza, M.; Pozzi, S.; The therapeutic strategy of HDAC6 inhibitors in lymphoproliferative disease. Int. J. Mol. Sci. 2018, 19, 2337. doi: 10.3390/ijms19082337;

[58] Hesham, H. M.; Lasheen, D. S.; Abouzid, K. A. M.; Chimeric HDAC inhibitors: Comprehensive review on the HDAC-based strategies developed to combat cancer. Med. Res. Rev. 2018, 38, 2058-2109. doi: 10.1002/med.21505;

[59] Lewis, K. A.; Jordan, H. R.; Tollefbols, T. O.; Effects of SAHA and EGCG on growth potentiation of triple-negative breast cancer cells. Cancers 2019, 11, 23. doi: 10.3390/cancers11010023;

[60] Bandolik, J. J.; Hamacher, A.; Schrenk, C.; Weishaupt, R.; Kassack, M. U.; Class I-histone deacetylase (HDAC) inhibition is superior to pan-HDAC inhibition in modulating cisplatin potency in high grade serous ovarian cancer cell lines. Int. J. Mol. Sci. 2019, 20, 3052. doi: 10.3390/ijms20123052;

[61] Laschanzky, R. S.; Humphrey, L. E.; Ma, J.; Smith, L. M.; Enke, T. J.; Shukla, S. K.; Dasgupta, A.; Singh, P. K.; Howell, G. M.; Brattain, M. G.; Ly, Q. P.; Black, A. R.; Black, J. D.; Selective inhibition of histone deacetylases 1/2/6 in combination with gemcitabine: A promising combination for pancreatic cancer therapy. Cancers 2019, 11, 1327. doi: 10.3390/cancers11091327;

[62] Najem, S. A.; Khawaja, G.; Hodroj, M. H.; Babikian, P.; Rizk, S.; Adjuvant epigenetic therapy of decitabine and suberoylanilide hydroxamic acid exerts anti-neoplastic effects in acute myeloid leukemia cells. Cells 2019, 8, 1480. doi: 10.3390/cells8121480; 
[63] Saha, S. K.; Yin, Y.; Kim, K.; Yang, G.-M,; Dayem, A. A.; Choi, H. Y.; Cho, S.-G.; Valproic acid induces endocytosis-mediated doxorubicin internalization and shows synergistic cytotoxic effects in hepatocellular carcinoma cells. Int. J. Mol. Sci. 2017, 18, 1048. doi: 10.3390/ijms18051048;

[64] Cerna, T.; Hrabeta, J.; Eckschlager, T.; Frei, E.; Schmeiser, H. H.; Arlt, V. M.; Stiborová, M.; The histone deacetylase inhibitor valproic acid exerts a synergistic cytotoxicity with the DNA-damaging drug ellipticine in neuroblastoma cells. Int. J. Mol. Sci. 2017, 18, 1048. doi: 10.3390/ijms19010164;

[65] Cuperlovic-Culf, M.; Touaibia, M.; St-Coeur, P.-D.; Poitras, J.; Morin, P. Jr.; Culf, A. S.; Metabolic effects of known and novel HDAC and SIRT inhibitors in glioblastomas independently or combined with temozolomide. Metabolites 2014, 4, 807-830. doi: 10.3390/metabo4030807;

[66] Chhabra, S.; Novel proteasome inhibitors and histone deacetylase inhibitors: Progress in myeloma therapeutics. Pharmaceuticals 2017, 10, 40. doi: 10.3390/ph10020040;

[67] Manzotti, G.; Ciarrocchi, A.; Sancisi, V.; Inhibition of BET proteins and histone deacetylase (HDACs): Crossing roads in cancer therapy. Cancers 2019, 11, 304. doi: 10.3390/cancers11030304;

[68] Natarajan, U.; Venkatesan, T.; Radhakrishnan, V.; Samuel, S.; Rathinavelu, A.; Differential mechanisms of cell death induced by HDAC inhibitor SAHA and MDM2 Inhibitor RG7388 in MCF-7 cells. Cells 2019, 8, 8. doi: 10.3390/cells8010008;

[69] Li, P.-T.; Tsai, Y.-J.; Lee, M.-J.; Chen, C.-T.; Increased histone deacetylase activity involved in the suppressed invasion of cancer cells survived from ALA-mediated photodynamic treatment. Int. J. Mol. Sci. 2015, 16, 23994-24010. doi: 10.3390/ijms161023994;

[70] Chiu, H.-W.; Yeh, Y.-L.; Ho, S.-Y.; Wu, Y.-H.; Wang, B.-J.; Huang, W.-J.; Ho, Y.-S.; Wang, Y.-J.; Chen, L.-C.; Tu, S.-H.; A new histone deacetylase inhibitor enhances radiation sensitivity through the induction of misfolded protein aggregation and autophagy in triple-negative breast cancer. Cancers 2019, 11, 1703. doi: 10.3390/cancers11111703;

[71] Moertl, S.; Payer, S.; Kell, R.; Winkler, K.; Anastasov, N.; Atkinson, M. J.; Comparison of radiosensitization by HDAC inhibitors CUDC-101 and SAHA in pancreatic cancer cells. Int. J. Mol. Sci. 2019, 20, 3259. doi: 10.3390/ijms20133259;

[72] Kalal, B. S.; Pai, V. R.; Behera, S. K.; Somashekarappa, H. M.; HDAC2 inhibitor valproic acid increases radiation sensitivity of drug-resistant melanoma cells. Med. Sci. 2019, 7, 51. doi: 10.3390/medsci7030051;

[73] Marchini, A.; Scott, E. M.; Rommelaere, J.; Overcoming barriers in oncolytic virotherapy with HDAC inhibitors and immune checkpoint blockade. Viruses 2016, 8, 9. doi: 10.3390/v8010009;

[74] Fox, C. R.; Parks, G. D.; Histone deacetylase inhibitors enhance cell killing and block interferon-beta synthesis elicited by infection with an oncolytic parainfluenza virus. Viruses 2019, 11, 431. doi: 10.3390/v11050431;

[75] Bassett, S. A.; Barnett, P. G.; The Role of dietary histone deacetylases (HDACs) inhibitors in health and disease. Nutrients 2014, 6, 4273-4301. doi: 10.3390/nu6104273;

[76] Merarchi, M.; Sethi, G.; Shanmugam, M. K.; Fan, L.; Arfuso, F.; Ahn, K.S.; Role of natural products in modulating histone deacetylases in cancer. Molecules 2019, 24, 1047. doi: 10.3390/molecules24061047;

[77] Peng, X.; Liao, G.; Sun, P.; Yu, Z.; Chen, J.; An overview of HDAC inhibitors and their synthetic routes. Curr. Top. Med. Chem. 2019, 19, 1005-1040. doi: 10.2174/1568026619666190227221507;

[78] Grant, S.; Easley, C.; Kirkpatrick, P.; Vorinostat. Nat. Rev. Drug Discov. 2007, 6, 21-22. doi: 10.1038/nrd2227;

[79] McGuire, C.; Lee, J.; Brief review of vorinostat. Clin. Med. Insights Ther. 2010, 2, 83-87. doi: 10.4137/CMT.S1102;

[80] Millard, C. J.; Watson, P. J.; Fairall, L.; Schwabe, J. W. R.; Targeting class I histone deacetylases in a “Complex" environment. Trends Pharmacol. Sci. 2017, 38, 363-377. doi: 10.1016/j.tips.2016.12.006;

[81] Subramanian, S.; Bates, S. E.; Wright, J. J.; Espinoza-Degado, I.; Piekarz, R. L.; Clinical toxicities of histone deacetylase inhibitors. Pharmaceuticals 2010, 3, 2751-2767. doi: 10.3390/ph3092751;

[82] Shah, R. R.; Safety and tolerability of histone deacetylase (HDAC) inhibitors in oncology. Drug Saf. 2019, 42, 235-245. doi: 10.1007/s40264-018-0773-9.;

[83] Lee, J.-H.; Choy, M. L.; Ngo, L.; Foster, S. S.; Marks, P. A.; Histone deacetylase inhibitor induces DNA damage, which normal but not transformed cells can repair. Proc. Natl. Acad. Sci. U.S.A. 2010, 107, 14639-14644. doi: 10.1073/pnas.1008522107; [84] Mottamal, M.; Zhen, S.; Huang, T. L.; Wang, G.; Histone deacetylase inhibitors in clinical studies as templates for new anticancer agents. Molecules 2015, 20, 3898-3941. doi: 10.3390/molecules20033898;

[85] Guandalini, L.; Cellai, C.; Laurenzana, A.; Scapecchi, S.; Paoletti, F.; Romanelli, M. N.; Design, synthesis and preliminary biological evaluation of new hydroxamate histone deacetylase inhibitors as potential antileukemic agents. Bioorg. Med. Chem. Lett. 2008, 18, 5071-5074. doi: 10.1016/j.bmcl.2008.07.119;

[86] Cellai, C.; Balliu, M.; Laurenzana, A.; Guandalini, L.; Matucci, R.; Miniati, D.; Torre, E.; Nebbioso, A.; Carafa, V.; Altucci, L.; Romanelli, M. N.; Paoletti, F.; The new low-toxic histone deacetylase inhibitor S-(2) induces apoptosis in various acute myeloid leukaemia cells. J. Cell. Mol. Med. 2012, 16, 1758-1765. doi: 10.1111/j.1582-4934.2011.01464.x;

[87] Guandalini, L.; Balliu, M.; Cellai, C.; Martino, M. V.; Nebbioso, A.; Mercurio, C.; Carafa, V.; Bartolucci, G.; Dei, S.; Manetti, D.; Teodori, E.; Scapecchi, S.; Altucci, L.; Paoletti, F.; Romanelli, M. N.; Design, synthesis and preliminary evaluation of a series of histone deacetylase inhibitors carrying a benzodiazepine ring. Eur. J. Med. Chem. 2013, 66, 56-68. doi: 10.1016/j.ejmech.2013.05.017;

[88] Binaschi, M.; Boldetti, A.; Gianni, M.; Maggi, C. A.; Gensini, M.; Bigioni, M.; Parlani, M.; Giolitti, A.; Fratelli, M.; Valli, C.; Terao, M.; Garattini, E. Antiproliferative and differentiating activities of a novel series of histone deacetylase inhibitors. ACS Med. Chem. Lett. 2010, 1, 411-415. doi: 10.1021/ml1001163; 
[89] Mieczkowski, A.; Koźmiński, W.; Jurczak, J.; A traceless, solid-supported synthesis of b-turn mimetics based on the hexahydropyrazino[1,2-a]pyrazine-1,2-dione scaffold. Synthesis 2010, 221-232. doi: 10.1055/s-0029-1217125;

[90] Mieczkowski, A.; Jurczak, J.; A Traceless solid-supported synthesis of novel pyrazinediazepinedione derivatives. Tetrahedron 2010, 66, 2514-2519. doi: 10.1016/j.tet.2010.01.064;

[91] Mieczkowski, A.; Speina, E.; Trzybiński, D.; Winiewska-Szajewska, M.; Wińska, P.; Borsuk, E. M.; Podsiadła-Białoskórska, M.; Przygodzki, T.; Drabikowski, K.; Stańczyk, L.; Zhukov, I.; Watala, C.; Woźniak, K.; Diketopiperazine-based, flexible tadalafil analogues: Synthesis, crystal structures and biological activity profile. Molecules 2021, 26, 794. doi: 10.3390/molecules26040794;

[92] Mieczkowski, A.; Trzybiński, D.; Wilczek, M.; Psurski, M.; Bagiński, M.; Bieszczad, B.; Mroczkowska, M.; Woźniak, K.; (S)-2-(4-Chlorobenzoyl)-1,2,3,4-tetrahydrobenzo[e]pyrazino[1,2-a][1,4]diazepine-6,12(11H,12aH)-dione-synthesis and crystallographic studies. Molbank 2017, 2017, M964. doi:10.3390/M964;

[93] Mieczkowski, A.; Psurski, M.; Bagiński, M.; Bieszczad, B.; Mroczkowska, M.; Wilczek, M.; Czajkowska, J.; Trzybiński, D.; Woźniak, K.; Wietrzyk, J.; Novel (S)-1,3,4,12a-tetrahydropyrazino[2,1-c][1,4]benzodiazepine-6,12(2H,11H)-dione derivatives: Selective inhibition of MV-4-11 biphenotypic B myelomonocytic leukemia cells' growth is accompanied by reactive oxygen species overproduction and apoptosis. Bioorg. Med. Chem. Lett. 2018, 28, 618-625. doi: 10.1016/j.bmcl.2018.01.034;

[94] Mieczkowski, A.; Frączyk, T.; Psurski, M.; Wińska, P.; Siedlecki, P.; Dziełak, M.; Trzybiński, D.; Wilczek, M.; Bagiński, M.; Bieszczad, B.; Woźniak, K.; Design and in vitro characterization of tricyclic benzodiazepine derivatives as potent and selective antileukemic agents. Chem. Biodivers. 2021, 19, e2000733. doi: 10.1002/cbdv.202000733;

[95] Bieszczad, B.; Garbicz, D.; Trzybiński, D.; Mielecki, D.; Woźniak, K.; Grzesiuk, E.; Mieczkowski A.; Unsymmetrically substituted dibenzo[b,f][1,5]-diazocine-6,12(5H,11H)dione - A convenient scaffold for bioactive molecule design. Molecules 2020, 25, 906. doi: 10.3390/molecules25040906;

[96] Bieszczad, B.; Garbicz, D.; Trzybiński, D.; Dudek, M.; Woźniak, K.; Grzesiuk, E.; Mieczkowski, A.; Unsymetrically-substituted 5,12-dihydrodibenzo[b,f][1,4]diazocine-6,11-dione scaffold - A useful tool for bioactive molecules design. Molecules 2020, 25, 2855. doi: 10.3390/molecules25122855;

[97] Bieszczad, B; Pawlędzio, S.; Polak, P.; Antonowicz, J.; Mieczkowski, A.; Trzybiński, D.; Influence of halogen size on the supramolecular and energy landscape of the THF solvates of the halogen derivatives of dianthranilide. CrystEngComm 2020, 22, 5389-5399. doi: 10.1039/D0CE00525H;

[98] Bieszczad, B.; Siwek, A.; Wilczek, M.; Trzybiński, D.; Woźniak, A.; Satała, G.; Bojarski, A.; Mieczkowski, A.; Synthesis, crystal structure and biological activity of novel analogues of tricyclic drugs" Bioorg. Med. Chem. Lett. 2020, 30, 127493. doi: 10.1016/j.bmcl.2020.127493;

[99] Duvic, M.; Vu, J.; Vorinostat: a new oral histone deacetylase inhibitor approved for cutaneous T-cell lymphoma. Expert Opin. Investig. Drugs 2007, 16, 1111-1120. doi: 10.1517/13543784.16.7.1111;

[100] Sastry, G.M.; Adzhigirey, M.; Day, T.; Annabhimoju, R.; Sherman, W.; Protein and ligand preparation: Parameters, protocols, and influence on virtual screening enrichments. J. Comput. Aid. Mol. Des. 2013, 27, 221-234. doi: 10.1007/s10822-013-9644-8;

[101] Schrödinger Release 2020-2: Protein Preparation Wizard; Epik, Schrödinger, LLC, New York, NY, 2016; Impact, Schrödinger, LLC, New York, NY, 2016; Prime, Schrödinger, LLC, New York, NY, 2020.

[102] Greenwood, J.R.; Calkins, D.; Sullivan, A.P.; Shelley, J.C.; Towards the comprehensive, rapid, and accurate prediction of the favorable tautomeric states of drug-like molecules in aqueous solution. J. Comput. Aided Mol. Des. 2010, 24, 591-604. doi: 10.1007/s10822-010-9349-1;

[103] Shelley, J.C.; Cholleti, A.; Frye, L; Greenwood, J.R.; Timlin, M.R.; Uchimaya, M.; Epik: a software program for pKa prediction and protonation state generation for drug-like molecules. J. Comp--Aided Mol. Des. 2007, 21, 681-691. doi: 10.1007/s10822-007-9133-z;

[104] Friesner, R.A.; Murphy, R.B.; Repasky, M.P.; Frye, L.L.; Greenwood, J.R.; Halgren,T.A.; Sanschagrin, P.C.; Mainz, D.T.; Extra precision glide: Docking and scoring incorporating a model of hydrophobic enclosure for protein-ligand complexes. J. Med. Chem. 2006, 49, 6177-6196. doi: 10.1021/jm051256o;

[105] Halgren, T.A.; Murphy, R.B.; Friesner, R.A.; Beard, H.S.; Frye, L.L.; Pollard, W.T.; Banks, J.L.; Glide: A new approach for rapid, accurate docking and scoring. 2. Enrichment factors in database screening. J. Med. Chem. 2004, 47, 1750-1759. doi: 10.1021/jm030644s;

[106] Friesner, R.A.; Banks, J.L.; Murphy, R.B.; Halgren, T.A.; Klicic, J.J.; Mainz, D.T.; Repasky, M.P.; Knoll, E.H.; Shaw, D.E.; Shelley, M.; Perry, J.K.; Francis, P.; Shenkin, P.S.; Glide: A new approach for rapid, accurate docking and scoring. 1. Method and assessment of docking accuracy. J. Med. Chem. 2004, 47, 1739-1749. doi: 10.1021/jm0306430; 